\title{
The Role of CALL in Vocabulary Acquisition through the Application of Learning Strategies
}

\author{
ManalAwad Mohammed Elwakeil \\ Sudan University of Science and Technology Graduate College \\ *Corresponding Author: ManalAwad Mohammed Elwakeil, Sudan University of Science and \\ Technology Graduate College
}

\begin{abstract}
The acronym CALL (Computer Assisted Language Learning) as stated by Chapelle (2001), was agreed upon at the 1983 TESOL convention to refer to the area of technology and second language teaching and learning. CALL was defined by Levy (1997) as 'the research and study of applications of computer in language teaching and learning', but Beatty (2003) shows awareness in the changing nature of CALL, and defines it as 'any process in which a learner uses a computer' resulting in the improvement of his/her language.Originally, CALL is a program derived from computer assisted learning with the aim to provide a tutorial program of language learning (Hartoye, 2008), but Egbert (2004) adds that CALL allows language learning in any context with, through, and around computer technologies. It is apparent from the definitions that the field of CALL involves the use of computer in language teaching and learning and its programs should entail different aspects of language learning processes via the computer. But CALL programs are necessarily determined by certain factors that shape the characteristics of any of its programs.
\end{abstract}

Keywords: CALL, acronym, TESOL, convention, technology, computer applications.

\section{INTRODUCTION}

Viewed from a historical perspective,CALL and its origin can be traced back in the 1960s with introduction of the PLATO system (Programmed Logic for Automated Teaching Operations). PLATO was originally built by the university of Illinois and functioned for four decades, offering course work (elementary - university) to students, local schools, and other tertiary institutions (Bitzor, 1960). At that time students worked on presentations and practices. Emphasis was mainly put on how to use the new technology rather the new technology's effects on learning.

Till late 1970s CALL projects were mainly confined to universities where computer programs were developed, but advances in size, and mobility of computer provided smaller, foster and powerful computers (Hanson - Smith, 2002).

That early CALL in the 1960s and 70s: considered with the dominants of the behaviorist theory of learning, as already mentioned at the beginning of this section, and was based mainly on them.. CALL Programs presented a stimulus to which the leaner had to provide a response. Programs of this phase entailed repetitive language drills presenting drills and non-judgment feedback (Taylor, 1998). The drill and practice models used the computer as a tutor or a vehicle for delivering instructional material to the learner (Ibid, 1980).

In that early phase of CALL's programs, the stimulus was in the form of a text presented on screen, and the only form in which the learner could respond was by entering an answer at the keyboard. One of the sophisticated systems was the PLATO system, which only ran on its own special PLATO hardware, including central computers and terminals. The PLATO system presented vocabulary, brief grammar explanation and drills (Rogers and Sussex, 1985). Higgins (1983) was among critics of that situation. They attributed it to Lack of imagination and skill on the part of programmers, a situation that was modified to a considerable extent by the publication of their influential seminal work which comprised an example of alternatives of approaches to CALL. Higgins and Johns triggered the debate of the early 1990s over mastership or slavery of computer to be a replacement for teachers or be merely an obedient servant to students?' cited in (Hans - Smith, 2002). 


\section{ROLE OF VOCABULARY IN ENHANCING LEARNING}

Vocabulary plays a crucial role in English language acquisition, particularly for collegestudents. Acquiring a deep and rich vocabulary knowledge-base can help thesestudents to convey their message more efficiently. However, learning vocabulary is not aneasy job. New words run fast out of mind if they are stored without any use. Practitionersand applied linguists have always been trying to not only emphasize the importance ofvocabulary learning but also propose a way for efficient learning of new vocabulary items.

Recently, learning strategies have been considered as influential tools for acceleratinglearning, especially language learning. Oxford (1994) mentions the critical role oflanguage learning strategies and defines them as behaviors, actions, and techniques that students apply to ameliorate their progress in producing andcomprehending L2. Learning the strategies makes learning faster and better.

Reckoning the issue, researchers like Gu (1994) and Schmitt (1997) applied theirknowledge of language learning strategies into vocabulary learning and they provided a subcategory of language learning strategies called "Vocabulary Learning Strategies" (VLS).Language learners must learn VLS for better learning of vocabularies because thisknowledge improves their process of acquisition. Making students aware of vocabularylearning strategies can be an influential method for teaching vocabularies. Manyresearchers emphasized the importance of vocabulary learning strategy use from differentperspectives. For example, Oxford (1990) suggests that language learners must beencouraged to use strategies in their process of learning. She adds that knowing vocabularylearning strategies makes learners autonomous and helps them in taking responsibility oftheir own learning. Benson (2001) also believes that explicit teaching of vocabularylearning strategies grows the level of independency in EFL/ESL learners. Nation (1990)believes that knowing and using vocabulary learning strategies is the most important wayfor learning language. Schmitt and Schmitt (1995) put that vocabulary learning strategiesknowledge is very important. The knowledge of vocabulary learning strategies must be ineducational programs and syllabuses. Holding the importance of strategies of learning forlanguage learning and the importance of learning enriching vocabulary items and enrichingvocabulary knowledge base, it is tried in this article to introduce most important vocabularylearning strategies that have been found as the most effective ones.

Foreign language acquisition research has recently come under strong criticism from a number of sources for the little attention it has paid to lexical acquisition. Much of the work that has been carried out has been concerned with lexical errors, but we are now beginning to realize that this data is very limited, and does not provide answers to some of the more important question we might want to ask about vocabulary acquisition (Meara, 1980, 1984, Levenston, 1979).

There are plenty of studies in the literature which demonstrate that cognitive factors and affective factors influence success in learning a foreign language, and the general methodology for investigating questions of this sort is well-established. Typically, researchers have either investigated a small number of variables using correlation methods, or they have made use of factor analysis techniques to summarize the relationships between a large numbers of variables (cf Gardner, 1980, 1985).

A particularly fruitful way of approaching these issues is to look at the strategies used by learners, and the effects these strategies have on success. Bialystok and Frolich, for instance, have shown that strategy use and attitude a related to success in language learning and we can infer from this that effective use of learning strategies is one of the factors that distinguish between good and poor learners. Unfortunately most of the studies have concentrated on identifying the strategies used for good learners.

\section{MiCro-STRATEgIES AND MACRO-STRATEGIES}

CALL develops the language learners' communication skills with convenience, accessibility, comfort and safety. They pick up language skills and improve efficiency faster. They can retain language skills longer and learn more about what they need. They are able to access materials to experience the interactions which would otherwise be difficult or impossible.

The present study shows that there is no absolute advantage in using a strategy that not all strategies have the same effect on all learners, and that choice of strategies is related to factors like attitude 
(Naiman et al, 1986). There is thus some advantage in approaching the question of strategies with an open mind, and making systematic comparison between the strategies used by good learners and those used by poor learners. As far as I know, the question of whether good and poor learners can be distinguished by their use of vocabulary learning strategies has not been asked before. It is possible to approach this question on two different levels. Firstly, one can study general approaches to learning, what Scholfield calls "macro- strategies" (Scholfieldfarohcoming). Alternatively, one can look at the more detailed, specific learner behaviors or "micro-strategies". For example, at the macro-strategy level, most good learners engage in what might be called "practice". However, some learners use specific micro-strategies in their practice which do not appear in the behavior of their learners; for instance, some learners test themselves systematically as part of their practice, while others do not. Most of the relevant study has concentrated on the holistic macro-strategy level, rather than the atomistic micro-strategy level, and this has led to the similarities between good learners being inflated.

Statements like "the good learners practice" are not really helpful. What we need are more specific findings which tell us what the learners actually do when they practice. This information would help us to deal with the differences between good and poor learners more adequately and help us to establish the effectiveness of particular micro-strategies.

The study reported in this paper had the following objectives:

a) To explain the role of vocabulary learning strategies in a foreign language acquisition.

b) To identify the types of micro-strategies used by a group of learners of English, and to assess how frequently these strategies were used.

c) To discover whether there were any differences in the strategies used by good and poor learners.

\subsection{List of Micro-Strategies and Macro-Strategies used by the Learners}

- Macro-strategies

Information

Sources

- Micro-strategies

Ask classmates- guessing- ask teacher - overlook - ask for L2 paraphrase - ask for L1 equivalent - ask for example of use - group work - dictionary.

- Dictionary use

Monolingual dictionary - bilingual dictionary - look up meaning - look up derivation - look up word class - look for example of use.

\section{- Memorization}

Write and repeat aloud - repeat aloud - write, repeat and L2 synonyms - write, repeat and L1 equivalent.

\section{- Practice}

Using new word in real situation - using new word in imaginary situation - ask for test - ask others to verify knowledge - use written sources to verify knowledge - self - test.

\section{- Preferred Source of Information}

Asking somebody - group work - dictionary.

- Note - taking

Taking notes at all notes in margin - vocabulary book - ordering new words sequentially organizing words by meaning - spelling information - L1equivalent - L2 synonym - word derivation grammatical information.

The results of the above analysis show that at the macro-strategy level, there is little to distinguish between good and poor learners. In particular, three macro-strategies appear to be common to all learners: A. Using sources to find out about difficult words. B. Memorization. C. Note-taking.

The main difference between learners lies in the choice of specific micro-strategies within these broad categories, and the presence or absence of the macro-strategy of practice. 
The second interesting and unexpected point to arise from this analysis is the importance of the groupwork strategy. Co-operation is basically a micro-strategy used by poor learners when they are faced with a difficult task.

\section{KEY WORD METHOD}

It is one of the most influential strategies of vocabulary learning, (Nation,2001). "It is a two-step mnemonic technique for learning foreign vocabulary items and theirEnglish equivalents". (Atkinson \& Rough, 1975; as cited in Crutcher, 1990). In this method,learners must find a part of the word which is similar for them in the sound, shape, ormeaning to something in their mind or language, and use it as a keyword. Then, they mustimagine a picture in their mind which relates both the word and the keyword together. Forexample, Transientwhen used as an adjective, transient describes something that existsfor a short period of time then is gone. Transient is pronounced "tran see ent". A briefdefinition of transient is "short-lived, ephemeral". To create a strong mental link for thisdefinition, we can encode the sounds of word "transient" and its meaning as mental images.

We do this by thinking of images to represent the phonetic sounds of the word anddefinition. To me, the word transient sounds very much like "train sees ant (Retrieved frommemory-improvementtips.com). It is believed that when this link is provided, the wordwill be retained for a long time.

\section{Vocabulary Flash Cards}

Nation and Webb (2010) consider learning vocabulary from flash needs highest level ofinvolvement. Based on Lockhart and Craik's (1972, as cited in Schmitt, 2008) level ofprocessing, if an activity has the highest level of involvement and deeper processing isneeded, the outcome of that activity is retained and learned better. Holding the level ofinvolvement, language learners must learn to use and to create their own flash cards if theywant to be successful in retaining vocabularies for a longer period of time. Nation (2001), in his comprehensive seminal book, namely, Learning Vocabulary in Another language,guides how to create and teach vocabulary items with flash cards.

\section{GUESSING FROM THE CONTEXT}

Incidental vocabulary learning is one of the methods of teaching vocabulary that if it isdone with intentional or instructed vocabulary learning, it will have very positive results.Guessing from the context is the most famous strategy of incidental vocabulary learning.Helping students on how to guess from the context and using clues in the text can not onlyincrease their speed in reading but also helps them to learn vocabularies in association withthe related contexts.

\section{WORD PARTS}

Learning word parts like affixes, prefixes, infixes, circum-fixes, and roots of the words is animportant strategy that learners can use to guess the meaning of the words fast. Scholarslike Nation (1990) and Schmitt (1997) believe that teaching word parts to students isessential. Students who learn the word parts can analyze the unknown words and not onlyguess the meaning faster but also increase their speed in reading or whatever task they aredoing that contains new vocabulary items for them. Thus, it is strongly recommended thatteachers teach word parts to students to help them expand their vocabulary knowledge basequickly.

\section{REPETITION}

The last important strategy that is mostly teacher-oriented is repetition. The scholars mostlybelieve that there must be at least seven times of exposure to take place for every word tobe learned efficiently. Nation (2001) believes that Pimsleur's model of repetition is veryapplicable for vocabulary learning. Based on Pimsleur's graduated-interval recall, intervalsmust be 5 seconds, 25 seconds, 2 minutes, 10 minutes, 1 hour, 5 hours, 1 day, 5 days, 25days, 4 months, and 2 years. Teachers must aware students of this spaced repetitionschedule to help them in their vocabulary retention. Moreover, nation (2001), in his book, has also provided different methods of repetition that can take place in classroom in details.

\section{Selecting Vocabulary}

Understanding the nature of vocabulary is important to the process of selecting appropriate instructional strategies that enable students to master the vocabulary they need to learn to read and to 
read to learn. Vocabulary consists of function words and content words. Function words are common words, such as are, that, and to. Content words include nouns, verbs, adjectives, and adverbs, like flower, eat, beautiful, and sadly. Further, content words are comprised of both concrete and abstract words. Concrete words, such as automobile, can be taught using an object or showing a picture. Abstract words, like harmony, are more easily taught using examples and non-examples. Finally, words may be considered to belong to either general vocabulary or technical vocabulary. General vocabulary refers to words, such as giant, that are not directly associated with a particular content area, while technical vocabulary, like mitosis, and is associated with a specific content area, subject, or topic.

The first step in planning for vocabulary instruction is to identify the words students will learn. Suggestions to guide you in this decision-making process are enumerated below.

Select words that are common or generally useful for students to know. Select words that students will encounter frequently, and that therefore, represent common knowledge (Marinak, Moore, Henk, \& Keepers, 1997).

1. Avoid assigning words that students rarely encounter (Ellis \& Farmer, 1996-2000). Less is more.

2. Choose terms that are strategic to academic success and are not typically acquired independently (Baker, et al., 1995). Emphasize terms critical to the student's understanding of the reading passage or unit of study, such as terms identified as "essential knowledge" in Virginia's Standards of Learning teacher resource guides.

3. Identify words that are essential for understanding a reading selection. Ask, "If readers did not know the meaning of this word, would they still be able to understand the passage?" If the answer is 'Yes', the word is probably not essential to understanding the selection's major concepts or ideas" (Marinak, et al., 1997, p. 1).

4. Pick textbook vocabulary that addresses key concepts or ideas. Each chapter of a subject area text may include a list of 15-20 vocabulary words. Often, only four or five of these terms address critical concepts of the chapter (Ellis \& Farmer, 1996-2000).

\section{SELECTING GOALS FOR VOCABULARY INSTRUCTION}

The second step in planning for vocabulary instruction is to determine the depth to which students will be required to understand each term you have selected. Some words warrant only a minimum level of knowledge, that is, a level of understanding that calls upon students to associate a new word with a definition, synonym, or context. However, if comprehension of the term is required, the teacher must select instructional strategies that enable students to categorize words, complete sentences, or generate multiple meanings for words. Finally, when academic demands require a deep level of understanding of terms, it is important that students be able to create original sentences using the words, make connections between new and prior knowledge, and apply word meanings across contexts (Baker et al., 1995).

\section{General GUIDELINES FOR TEACHing Vocabulary}

It is helpful to keep in mind several general principles that facilitate acquisition of new vocabulary.

- Teach new words in the context of a meaningful subject-matter lesson and facilitate student discussion that requires students to use the new word (Ellis \& Farmer, 1996-2000).

- Ensure that students hear the correct pronunciation of the word and practice saying it aloud. Hearing the syllable structure and stress pattern of the word facilitates its storage in memory (Fay $\&$ Culter, 1977).

- Teach word parts - root words, base words, prefixes, and suffixes that students will encounter frequently (Jones, 1999).

- Teach words in related clusters to help students understand how words are related and interrelated (Marinak, et al., 1997).

- Identify examples/applications and non examples/non applications related to the meaning of the new word (Ellis \& Farmer, 1996-2000). 
- Help students connect new vocabulary to something with which they are already familiar (Ellis \& Farmer, 1996-2000).

- Create opportunities for students to paraphrase the definition of a new term so that they can identify the main idea associated with the term and recognize specific bits of information that clarify its broader, more general core idea (Ellis \& Farmer, 1996-2000).

- Offer students the opportunity to acquire new vocabulary using a variety of learning modalities or formats that actively engage them in the learning process (Ellis \& Farmer, 1996-2000).

\section{ACTIVITIES FOR TEACHING VOCABUlaRY}

After you have strategically selected vocabulary words for instruction and determined the appropriate instructional goals for chosen terms, it is time to identify instructional strategies that align with these goals. The activities suggested below employ a variety of formats to address the goals of vocabulary instruction.

\section{SAME WORD, DifFERENT SUBJECT}

1. Explain to students that each school subject consists of technical vocabulary words and specialized words. Technical words are those that usually have only one meaning and are discussed in only one subject. For example: English - verb, gerund biology - mitosis mathematics and rhombus.

2. Tell students that specialized vocabulary words are those that are used in different subjects and usually have different meanings in each subject. For example, the word division could be used differently in history, mathematics, and science classes.

3. Have students identify and discuss other specialized vocabulary words. Create a class list that can be added to regularly as new words are encountered and discussed.

\section{Vocabulary SELF-COLlection STRATEgy}

1. Ask students to identify two words they believe everyone should learn that are related to specific topics the group is studying.

2. Have students write their words on the board.

3. Ask students to present their words to the group by defining them, explaining why the group should learn them, and telling where the words were found.

4. Moderate a discussion through which the class reduces the list to a predetermined number of most important words by eliminating words already known by many. The final list becomes the focus of vocabulary activities for the next few days.

\section{SCAVENGER HunT}

1. Give students a list of essential vocabulary they must know for a unit they are studying.

2. Organize students into small groups - usually three or four students per group.

3. Provide student groups with time to search for the new words using reference books, newspapers, magazines, websites, and other appropriate resources at school and at home. Instruct students to collect examples of the words, copy sentences that use the words, collect or draw pictures of the words, and build models or examples of the words. Assign point values for each of these methods of illustrating the vocabulary words, for example: 8 points for building a model representing the word, 5 points for finding a newspaper/magazine article that uses the word and 2 points for finding a book about the word or illustration that describes the word. You may also wish to award bonus points for groups that find a representation for all vocabulary words on the list.

4. Allow groups to meet each day for a few minutes to plan a strategy for gathering the representations of their words and assess how they are progressing in their collection efforts. Tell groups to keep their progress and findings secret; they are competing with the other groups for points.

5. Create posters on which vocabulary words are written (one word per poster). On the day that the items/examples are due, give groups a few minutes to organize their objects in piles by the words 
written on the posters. Show each word poster and have students, group by group, share what they have brought to represent that word. Briefly record their ideas on each word poster. Post these posters on the wall.

6. Next, have groups sort their items by type. For example, put books about the topics in one pile, pictures in another pile, and models in yet another pile.

7. As the unit is taught, students can refer to the posters to review these essential vocabulary words. The teacher may also ask students to use the list of scavenger hunt words to write a summary of the unit.

\section{PINWHEEL}

1. Divide the class into groups of 6,8 , or 10. Each group forms an outer and an inner circle. Innercircle students face out; outer-circle students face in, in such a way that each member of the inner circle is facing a partner in the outer circle. The outer circle partner faces his inner-circle partner as well.

2. Each inner-circle student is given a different vocabulary word and its corresponding definition. The inner-circle students quiz their partners on the meaning of their vocabulary words. Inner-circle partners may offer assistance, as needed.

3. After each dyad has completed reviewing its assigned word and its corresponding definition, the outside students are cued by the teacher to "pinwheel" or move one position to the right. Now, each student has a new partner, and the outside students have new vocabulary words to review. This process continues until each outside student has worked with each inside student.

4. Call, "Inside out and outside in." Students switch roles and the process is repeated.

\section{The Chain Game}

This game may be played by groups of eight students after the class has studied the vocabulary in a specific lesson or unit of study. It provides much repetition of words and their definitions.

1. Draw eight links on the blackboard or overhead projector to create a chain, and write a vocabulary word in each link.

2. Select the first player in each group. This student chooses any word in the chain, reads the chosen word, and defines it.

3. Select the second player in each group. This student determines the direction of play on the chain by choosing a word to the right or the left of the word selected by the first player in the chain. The second player in each group reads and defines the word selected by the first player, then reads the word he or she has chosen and defines it.

4. Select successive players. Each of these players reads and defines previously selected words in the order in which his or her predecessors chose them, then reads and defines the next word in the chain.

Note: When the teacher selects the students, the difficulty of the task can be controlled for students who have memory deficits. Some students with memory difficulties prefer to have their turn early in the game. Some at-risk students prefer to take a turn later in the game, and take pride in repeating definition after definition, which they have learned because of the intensity of the repetition.

\section{Vocabulary CharadeS}

1. Put words that describe visual concepts on cards. (Examples: hurricane, motivate).

2. Divide the class into teams.

3. Ask a member of each team, in turn, to draw a card and "act it out."

4. Determine a time limit by which teammates must guess the word being acted out. Assign points for each word guessed correctly by the teams.

5. Continue until all members of each team have had an opportunity to illustrate a word. 


\section{QUICK DRAW}

1. Put words that describe visual concepts on cards.

2. Divide the class into teams. Ask a member of each team, in turn, to draw a card.

3. Have the student see how quickly team-mates can convey the essence of a word on the board without words - by illustrating it.

4. Continues until all members of each team have had an opportunity to illustrate a word.

\section{Concentration}

Student pairs can play this game after studying the vocabulary in a lesson or unit.

1. Pairs of students spread out word cards and matching definition cards face down in random order in front of them on a flat desk, table, or floor.

2. Students take turns flipping over pairs of cards to try to find matching words and definitions. Each time a student finds a matching pair of cards; he or she removes them from the playing area and keeps them.

3. The student who has acquired the most cards after all cards have been removed from the playing surface wins.

\section{JEOPARDY}

This game can be played with the whole class after studying the vocabulary in a unit of study.

1. Create cards that contain the definitions of key vocabulary students have studied.

2. Determine categories for these definitions.

3. Choose five definition cards per category. Assign point values to definitions according to their level of difficulty. Write the appropriate point value on the back of each definition card.

4. Organize the category labels and definitions (face down) into a Jeopardy game board on the blackboard.

5. Divide the class into two teams.

6. In turn, have the members of each team call out a category and card (by point value). Read the definition written on the card selected. If the student who selected the card can provide the word for the definition read, his team receives the assigned number of points.

7. The team with the most points wins the game.

\section{Class-Wide Peer Tutoring}

Divide the class into two "balanced" teams. Assign tutoring pairs within each team.

1. Prepare flashcards with vocabulary terms on one side and their definitions on the other side. (Instead of flashcards the students may use class notes taken in two-column form, with words on the left side and definitions on the right side of the page.)

2. Students take turns being the tutor and tutee during tutoring time; the teacher supervises the interactions, making note of difficult vocabulary.

3. Tutees earn points by giving correct definitions to words called out to them by their tutors. If the correct response is given initially, a predetermined number of points are awarded. If the tutee corrects an erroneous answer independently, he is awarded points as well, albeit fewer points than he would have earned if his first answer had been correct. The teacher may award bonus points for on-task tutoring and responding behaviors.Rewards are provided for points earned during tutoring sessions. Teachers may, for example, factor points into student homework grades.

\section{CONCLUSION}

In this paper, the most important vocabulary learning strategies were enlisted. These fivestrategies are found to be the most influential vocabulary learning strategies. Languageteachers are recommended to consider teaching at least these five strategies becausewithout vocabularies no one can convey meaning.This paper has shown that in the process of learning new words the main distinguishing feature is that "good" learners typically use the macro-strategy of practice, while "poor" learners do not. This analysis has also proved that patterns of vocabulary learning strategies deserve further detailed investigation. The results of the analysis support the view that most progress is likely to be made at the level of micro-strategy use, and that this atomistic type of approach of more likely to contribute to our understanding of vocabulary acquisition than the more common holistic approach to 
strategies. We can say that there is a role of vocabulary learning strategies in the process of foreign language acquisition. Also, there is a difference between the vocabulary learningstrategies used by good learners and those used by underachieving learners. Good learners not only use more strategies, but they also rely more heavily on different strategies than the ones poor learners use. There are strategies used by good learners and others used by underachieving learners. Good learners not only use more strategies, but they also rely more heavily on different strategies than the ones poor learners use. However, the analysis showed that neither of these two groups is homogeneous: different subtypes can be distinguished for both good and underachieving learners.

\section{REFERENCES}

[1] Benson, P. (2001). Teaching and researching: Autonomy in language learning. London:Longman.

[2] Crutcher, R. J. (1990). The role of mediation in knowledge acquisition and retention:Learning foreign vocabulary using the keyword method (Report No. 90-10).Institute of Cognitive Science: University of Colorado, Colorado.

[3] He, Y. (2010). A study of L2 vocabulary learning strategies (Unpublished masterdissertation). Kristiansatd University, Sweeden.

[4] http://www.memory-improvement-tips.com/memorizing-vocabulary.html

[5] Nation, I. S. (2001). Learning vocabulary in another language. Cambridge: CambridgeUniversity Press.

[6] Nation, I. S. P. (1990). Teaching and learning vocabulary. Boston, Mass.: Heinle\&Heinle.

[7] Nation, I. S. P., \& Webb, S. (2010). Researching and analyzing vocabulary. Heinle:Boston.

[8] Oxford, R. (1990). Language learning strategies: What every teacher should know.Boston: Newbury House.

[9] Schmitt N., \& Schmitt, D. (1995). Vocabulary notebooks: theoretical underpinnings andpractical suggestions. ELT Journal, 49, 133-243.

[10] Schmitt, N. (1997). Vocabulary learning strategies. In N. Schmitt \& M. McCarthy (Eds.).

[11] Vocabulary: description, acquisition and pedagogy (pp.199-228). Cambridge:Cambridge University Press.

[12] Schmitt, N. (2008). Review Article: Instructed second language vocabulary learning.

[13] Bialystok, E., Frolich, M., Oral communication strategies, Inter-language Studies Bulletin, 5,1, 1980, p.330 ;

[14] Gardner, R., On the validity of affective variables in second language acquisition: conceptual, contextual and statistical.

[15] Levenstone, E.A., Second language vocabulary acquisition: issues and problems, Inter-language Studies Bulletin, 4,2, 1979, p.147-160;

[16] Meara, P., Vocabulary acquisition: a neglected aspect of language learning, Language Teaching and Linguistics Abstracts, 13,4, 1980, p.221-246;

[17] O’Malley, J., Learning strategies used by beginning and intermediate ESL students, Language Learning, 35, 1, 1985, p.21-46;

[18] Scholfield, P., Cluster analysis in the study language variation, farthcoming.

\section{AUTHOR'S BIOGRAPHY}

Ms. Manal is a lecturer at the Department of English, College of Education, Gedarif University, Sudan. She is recently working for the Department of English, College of Science and Humanities, Prince Sattam University, KSA. Currently she is a Ph.D candidate at College of Languages, Sudan University of Science and Technology. Ms. Manal obtained her bachelor degree in English from Omdurman Islamic University, College of Arts in 1996. She received her Post-Graduate Diploma in English Language Teaching in 2000 from Khartoum University, College of Education and her master degree in linguistics in 2001 from the same university and college. Ms. Manal areas of interest include Computer Assisted Language Learning (CALL), E-learning and English Language Teaching (ELT).

Citation: ManalAwad, Mohammed Elwakeil. "The Role of CALL in Vocabulary Acquisition through the Application of Learning Strategies." International Journal on Studies in English Language and Literature (IJSELL), vol 5, no. 10, 2017, pp. 59-67. http://dx.doi.org/10.20431/2347-3134.0510008.

Copyright: () 2017 Authors. This is an open-access article distributed under the terms of the Creative Commons Attribution License, which permits unrestricted use, distribution, and reproduction in any medium, provided the original author and source are credited. 